\title{
MOLECULAR DOCKING STUDY OF NUTMEG (Myristica Fragrans) CONSTITUENTS AS ANTI-SKIN CANCER AGENTS
}

\author{
$\underline{\text { Ika Nur Fitriani }}^{1^{*}}{ }^{\text {and Hery Muhamad Ansory }}{ }^{2}$
}

${ }^{1}$ Department of Chemistry, Faculty of Science and Technology, UIN Walisongo Jl. Walisongo No.3-5, Tambakaji, Ngaliyan, Semarang, Jawa Tengah 50185, Indonesia

${ }^{2}$ Faculty of Pharmacy, Universitas Setia Budi Surakarta

Jl. Letjen Sutoyo, Mojosongo, Jebres, Surakarta, Jawa Tengah 57127, Indonesia

* Correspondence: email: ikanurf@walisongo.ac.id

\section{ABSTRACT}

Molecular docking analysis was carried out to understand better the interaction between DHODH and inhibitor from nutmeg in this series. The nutmeg constituent binding orientations in the active site of DHODH was seen in a molecular docking analysis and helped design a potentially new inhibitor. This work aimed to study the molecular docking of nutmeg constituents with the DHODH inhibitor using a computer-aided drug design. Molecular docking using AutoDock 4.2 was done to explore the models of binding complexes. The 3D structure was derived using Discovery Studio to investigate the essential chemical interaction of complex structures. Dihydroguaiaretic acid was the most potent ligand having a docking score of $-9.3 \mathrm{kcal} / \mathrm{mol}$. This value was better than the standard drug 5-FU. The dihydroguaiaretic acid structure interacted with Tyr365 and Thr63 through a hydrogen bond similar to the native ligand. These results suggest that nutmeg seed could serve as the lead compound for potent DHODH inhibitors against skin.

Keywords: $D H O D H$, molecular docking, nutmeg, skin-cancer

\section{INTRODUCTION}

Nutmeg (Myristica fragrans) extracted from the seed of nutmeg used for medicinal purposes [1]. Nutmeg oil is acquired from the seed of nutmeg fruit. The essential oil from nutmeg seeds has anticarcinogenic activity [2]. Studies on the nutmeg seed have reported extracts and many compounds with anti-cancer and antioxidants activities [3,4].

A flavonoid found in nutmeg shows that anti-cancer potent effects, mostly on UV$B$, cause skin cancer, but molecular mechanisms and targets are open to questions [5]. Skin cancer in 2018 is the second biggest cancer cause of death worldwide, with new cases, approximately 9.88 million, and 1.08 million were monitored. Melanoma cancer rapidly increases than nonmelanoma cancer because of environmental changes. Skin cancer/melanoma is rising in current years due to exposure to UV radiation. Almost the aggressiveness of skin cancer caused by exposure to an excess of UV radiation from the sun [6]. 
Dihydroorotate dehydrogenase $(\mathrm{DHODH})$, located in the internal mitochondrial membrane, plays a key function in the programming of UV-B induced energy. DHODH catalyzes the transformation of dihydroorotate in the fourth step of the six enzyme reactions of this pathway as the ratelimiting enzyme in the de novo pyrimidine synthesis pathway. DHODH up-regulation was crucial for sustaining higher activity in the radiated skin of the electron transport chain and for coordinating ATP generation [7]. Enhanced DHODH activity was involved as a biomarker for malignant tumours, including skin cancer. Ultraviolet radiation can induce DHODH expression transcriptionally by triggering STAT-3 [8]. DHODHODH inhibitors affect ATP depletion and endogenous ROS levels. A DHODH inhibitor proved an antitumour treatment effect in conjunction with fluorouracil [9]. DHODHODH inhibitors have great potential to be used for cancer treatment [9-13].

Melanoma skin cancer has a strong potency to grow to other parts of the body, and it becomes difficult to cure. The WHO reports that 132,000 cases of skin cancer happen on an annual basis. In 2016, approximately 76,380 skin cancer cases will be invading melanomas, with about 46,870 in males and 29,510 in women. There will be an annual increase of skin cancer impact by 4500 due to the $10 \%$ devastation of the ozone layer [14].

The invention of new bioactive compounds shows highly selective anticancer activity is of high order for cancer treatment. Possible anti-cancer activities of myristicin were predicted by computer- based molecular docking. This study includes molecular docking of myristicin from nutmeg against active centres of cancer-related DHODH [14]. New research is still required in finding new compounds for skin cancer. Finding a specific target drug is one of the most effective ways to inhibit skin cancer [15].

Molecular docking is a tool for predicting small molecules' binding orientation from drug candidates to their protein targets to predict the activity and affinity. Molecular docking plays a major role in the design of drugs. Autodock is one of the programs used to perform docking [16]. Several molecular docking works from phytochemical constituents for anti-cancer have been published elsewhere [17] [18] [19]. The molecular docking of nutmeg constituent toward DHODH for skin cancer has never been reported before.

The investigation of the binding site between the $\mathrm{DHODH}$ receptor and the selected structure from nutmeg was done. A docking score evaluation was also carried out for investigating the anti-cancer activity. This research examines the interaction binding site between nutmeg seed constituents and DHODH as anti-skin cancer agents.

\section{METHODS}

The ligands and receptor protein were prepared using Chimera 1.13.1 and Autodock 4.2.6 (The Scripps Research Institute, USA). Autodock Tools (ADT) 1.5.6 were used for the docking analysis. Computational visualization was performed using Discovery Studio (BIOVIA Discovery Studio 2019). The hardware used was Asus VivoBook Intel 
Core i3-7020u, 4GB RAM, and 500GB hard disk using OS Windows 10.

The 3D structure of 20 ligands from nutmeg constituents was obtained using the Pubchem web database. The ligand was prepared to pdbqt format using Chimera 1.13.1. The 3D structure of $\mathrm{DHODH}$ was obtained from Protein Data Bank (www.rscb.org/pdb) using PDB ID (PDB entry: 2BXV) [20], resolution of $2.15 \AA$, organism Homo sapiens) in the database. The receptor protein was prepared using Chimera 1.13.1. All water molecules were removed, and hydrogen atoms were added.

The binding mode of the nutmeg seed active compound into the target of $\mathrm{DHODH}$ was investigated using molecular docking [21]. The pdbqt files for protein and ligands preparation and generating the grid box were completed using the graphical user interface program AutoDock Tools (ADT). AutoGrid was used for the preparation of the grid map using a grid box. The grid size was set to $38.88 \times 44.27 \times 42.81 \mathrm{XYZ}$ points. The ligand was docked into the active sites of melanoma skin cancer (PDB ID: 2BXV).

Lamarckian genetic algorithm (LGA) was used to detect the most desirable ligand binding orientations. The interaction was produced, and the docking result of binding energy and residue were reported [22, 23]. The dock Score function was used to scoring all the dock ligands. Analyses were identified from the best pose.

\section{RESULTS AND DISCUSSION}

The application of molecular docking used in medicinal chemistry and drug discovery is predicted the interaction between two molecules. Docking is done between a small molecule drug and a large macromolecule receptor in drug discovery. Molecular mechanics apply for most docking program to calculate the binding energy [24]. Docking is useful for drug design by searching the optimized confirmation for the ligan-protein complex and their relative orientation. Minimum free energy in the overall system means the ligand is potent to select drug candidates [25]. There are three steps in molecular docking: pose prediction, virtual screening, and binding affinity calculation-Ligan conformation generated from the search algorithm and energy scoring function [26].

Molecular docking studies in this work were done using the AutoDock Tools (ADT) 1.5.6 and AutoDock 4.2.5.1 docking program. The docking program is used to explore the potential binding mode of the inhibitor from the nutmeg constituents. Nutmeg seeds essential oil have anticarcinogenic activity. The composition of nutmeg seed oil differ significantly based on their source. The essential oil of nutmeg seed contains sabinene $(15-50 \%)$, a-pinene $(10-22 \%)$, bpinene (7-18\%), myrcene $(0,7-3 \%)$, 1.8cineole (1,5-3,5\%), a-phellandrene (0,3$6.2 \%)$, myristicin $(0,5-13,5 \%)$, limonene (2,7$4,1 \%)$, eugenol $(0,1-1 \%)$, safrole $(0,1-3,2 \%)$, and terpinene-4-ol (0-11\%) [27]. The potential chemopreventive agent in volatile oil is elemicin, and the most responsible for pharmacological effect in nutmeg is myristicin [28]. The main compounds in the aromatic essential oil are myristicin, elemicin, safrole (85-95\%), and myristicin (4-12\%) [29]. 
The algorithm of molecular docking had been originally tested by redocking ligands at the active receptor position for the reliability and reproductivity of the current docking algorithm, utilizing the root mean square deviation (RMSD) measurement. RMSD from redocking of 2XBV protein receptor was $1.733 \AA$. RMSD value less than $2.0 \AA$ showing the algorithm validated compared to the crystallographic structure [30]. As can be seen from the comparison of our RMSD with the RMSD as mentioned above, this research could continue using our validated docking protocol [31]. The RMSD below $2.0 \AA$ indicates the formation of good quality docking method [32].

Molecular docking has many benefits, including the system's capacity to check broad compound databases at low costs compared to experiments [33]. Molecular modelling is used to predict the compound's possible mode and determine the direction of the best pose from the optimizing structure [34]. Twenty compounds from nutmeg seed were docked to binding sites of the DHODH target. The calculated binding energy corresponds to the anti-cancer activity [35]. The docking score and interaction residue of the $\mathrm{H}$-bond presented in Table 1. The best-docked ligand was the malignant compound. The binding energy of malignant with the $\mathrm{DHODH}$ is $-10.4 \mathrm{kcal} / \mathrm{mol}$.

Alpha-pinene performed low binding energy scores, respectively $-6.0 \mathrm{kcal} / \mathrm{mol}$. The low binding energy because the compound did not fit with the binding site of the DHODH receptor. The $\Delta \mathrm{G}$ binding of 19 constituents from nutmeg was all greater than $-7.0 \mathrm{kcal} / \mathrm{mol}$, suggesting that these nutmeg constituents have the potential to be $\mathrm{DHODH}$ inhibitor. A stable complex that shows greater negative free binding energy indicates high inhibitor strength [36]. Table 1 indicated that the selected compounds from nutmeg showed good anti-cancer activity compared with the 5 fluorouracil, which is widely used in cancer treatment. According to the results from the molecular docking studies for $\mathrm{DHODH}$, all nutmeg seed constituents performed significantly better scores when compared with 5-fluorouracil as drug standard [37] [38].

The docking score between DHODH and compound macilin $F$, macelignan, dihydroguaiaretic acid, and fragransin E1 was 10.0, -10.4, and 9.3 and -9.7 , respectively. The order of activity was: macelignan $>$ macilin $\mathrm{F}>$ fragransin E1 > dihydroguaiaretic acid. The docking score indicates the interaction affinity between the receptor and ligand by the optimized algorithm, speculating the scope of inhibitory activity. The evaluation index for fast preliminary steps and inhibitors is the key importance of the docking score.

The free binding free energy estimation is calculating from the docking score for the protein-ligand complex. The lowest energy score indicates the highest protein affinity with the best potent ligand means the best docking score [35]. The docking scores for each compound compared to the standard drug score. The result shows that the nutmeg constituents have better docking scores than standard drugs available in the market (5fluorouracil [38]. The active site exhibit that several molecular interactions considered in control of the observed affinity. After checked the binding score, evaluation of docking score based on amino acid residue between ligandreceptor complex. 
Table 1. Docking score of nutmeg constituents

\begin{tabular}{|c|c|c|c|c|c|}
\hline No & Compound name & $\begin{array}{l}\text { Docking } \\
\text { score } \Delta \mathrm{G} \\
\text { (kcal/mol) }\end{array}$ & $\begin{array}{l}\text { Interacting } \\
\text { residues }(\mathrm{H}- \\
\text { bond })\end{array}$ & $\begin{array}{l}\text { Interacting residue } \\
\text { (non-hydrogen bond) }\end{array}$ & References \\
\hline 1 & Dyclonin & -9.2 & Asn145 & $\begin{array}{c}\text { Val143, Tyr356, Pro52, Ala55, } \\
\text { Ala59 }\end{array}$ & [39] \\
\hline 2 & Dihydroguaiaretic acid & -9.3 & Tyr356, Thr63 & $\begin{array}{l}\text { Pro364, Phe98, Leu359, } \\
\text { Ala59, Thr360, Ala55 }\end{array}$ & [39] \\
\hline 3 & Eugenol & -7.0 & & Tyr356, Val143 & [39] \\
\hline 4 & Fragnasol A & -8.7 & $\begin{array}{l}\text { Lys } 255, \\
\text { Thr360 }\end{array}$ & Tyr356, Val134, Val143 & [39] \\
\hline 5 & Fragnasol C & -8.6 & Glin47 & $\begin{array}{l}\text { Met43, Leu42, Ala59, Leu58, } \\
\text { Pro364, Leu359, Met43 }\end{array}$ & [39] \\
\hline 6 & Fragransin A2 & -9.1 & & $\begin{array}{c}\text { Phe62, Leu46, Leu58, Ala59, } \\
\text { Ala55 }\end{array}$ & [39] \\
\hline 7 & Fragransin $\mathrm{C} 2$ & -8.5 & Thr63 & $\begin{array}{c}\text { Phe52, Leu42, Ala59, Tyr38, } \\
\text { Pro364, Met43, Ley46 }\end{array}$ & [39] \\
\hline 8 & Fragransin E1 & -9.7 & & $\begin{array}{l}\text { Arg136, Val143, Tyr356, Ala59, } \\
\text { Ala55, His56, Pro52, Val143 }\end{array}$ & [39] \\
\hline 9 & Fragransol B & -9.0 & Gln47 & $\begin{array}{c}\text { Met43, Pro364, Tyr356, } \\
\text { Leu359, Phe98 }\end{array}$ & [39] \\
\hline 10 & Guaiacin & -8.1 & Tyr356 & Ala96, Ala95 & [39] \\
\hline 11 & Isoeugenol & -7.4 & & Pro52, Val143, & [39] \\
\hline 12 & Macelignan & -10.4 & Ala96, Gln47 & $\begin{array}{c}\text { Tyr147, Val134, Tyr356, Ala55, } \\
\text { Thr360, Val143, Phe62, } \\
\text { Leu359, Phe98 }\end{array}$ & [39] \\
\hline 13 & Machilin F & -10.0 & & Ala59, Pro364, Leu46, Leu58 & [39] \\
\hline 14 & Methylisoeugenol & -7.7 & Asb145 & Val143 & [39] \\
\hline 15 & Myristic acid & -6.7 & $\begin{array}{l}\text { Ser305, } \\
\text { Asn145 }\end{array}$ & His56, Phe98, Ala59 & [39] \\
\hline 16 & Myristicanol A & -7.6 & & $\begin{array}{c}\text { Met43, Ala59, Leu42, Pro364, } \\
\text { Tyr38, Pro52 }\end{array}$ & [39] \\
\hline 17 & Myristicanol B & -8.0 & $\begin{array}{l}\text { Asn284, } \\
\text { Lys255 }\end{array}$ & Val143, Ala55, Ala34, Tyr147 & [39] \\
\hline 18 & Myristicin & -7.9 & Ser305 & Val143, Val134, Pro52 & [39] \\
\hline 19 & Safrole & -7.6 & $\begin{array}{l}\text { Asn145, } \\
\text { Ser305 }\end{array}$ & $\begin{array}{c}\text { Val143, Tyr356, Val135, Pro52, } \\
\text { Leu42, Pro364, Ala59 }\end{array}$ & [39] \\
\hline 20 & Alpha-pinene & -6.0 & & $\begin{array}{l}\text { Tyr38, Pro69, Leu68, Leu58, } \\
\text { Leu46, Phe62 }\end{array}$ & [39] \\
\hline 21 & Native ligand & -12.0 & Tyr356, Thr63 & $\begin{array}{c}\text { Thr360, Ala55, Leu359, Ala59, } \\
\text { Tyr38, Leu42, Pro364 }\end{array}$ & {$[20]$} \\
\hline 22 & 5-fluorouracil & -6.4 & $\begin{array}{l}\text { Asn145, } \\
\text { Asn217, } \\
\text { Asn284, } \\
\text { Asn212 }\end{array}$ & & \\
\hline
\end{tabular}

Interaction of nutmeg constituents and DHODH protein receptor can be seen in Table 1. Table 1 showed interacting residue hydrogen bond and non-hydrogen bond from 40 nutmeg constituent compared with native ligand and drug standard. Docking simu-lations colored 2D-binding mode represen-tation between
DHODH and native ligand shown in Figure 1. Macelignan-DHODH complex and dihydroguaiaretic acid-DHODH complex binding mode shown in Figure 2 and 3, respectively. The binding interactions between $\mathrm{DHODH}$ and nutmeg constituents mainly involve conventional hydrogen bonds, Van der 
Walls, pi-sigma, pi-alkyl, pi-pi stacked, and alkyl. Molecular docking reports showed that the compounds would interact in $\mathrm{DHODH}$ inhibitor. The binding between the bioactive compounds and $\mathrm{DHODH}$ was verified by molecular docking.

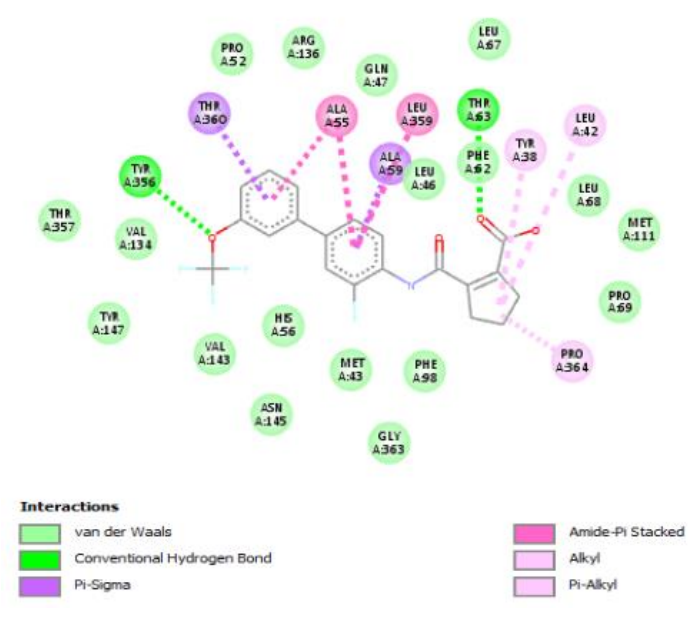

Figure 1. Two-dimensional interaction of native ligand and $\mathrm{DHODH}$

There is no hydrogen bond in macilin $\mathrm{F}$ and fragransin E1. They interact only through alkyl and $\pi$-alkyl interaction. Native ligandbound Tyr356 and Thr63 via hydrogen bond. The hydrogen bonds between Ala96, Gln47 residues and macelignan, the pi-pi stacked between Thr360 and macelignan, or pi-alkyl bonds between Ala55, Val143, Val134, Tyr356, Tyr147 and macelignan, not related to the native ligand interaction and $\mathrm{DHODH}$. Two-dimensional interaction of malignant and DHODH could be seen in Figure 2.

The interaction of dihydroguaiaretic acid has two hydrogen bonds with amino acid, namely Thr63 and Tyr365, similar to the native ligand. Dihydroguaiaretic acid could strongly interact with Thr63 and Tyr635 via carbonhydrogen. This association was powered by the forming of hydrogen interactions between the receptor and the compound. The $\pi$-sigma interaction found in Ala59 and Thr360. The $\pi-$ alkyl interaction found in Pro364. The twodimensional interaction of dihydroguaiaretic acid could be seen in Figure 3. Dihydroguaiaretic acid has the best interaction in complex DHODH because of the amino acid residue similar with native ligand.

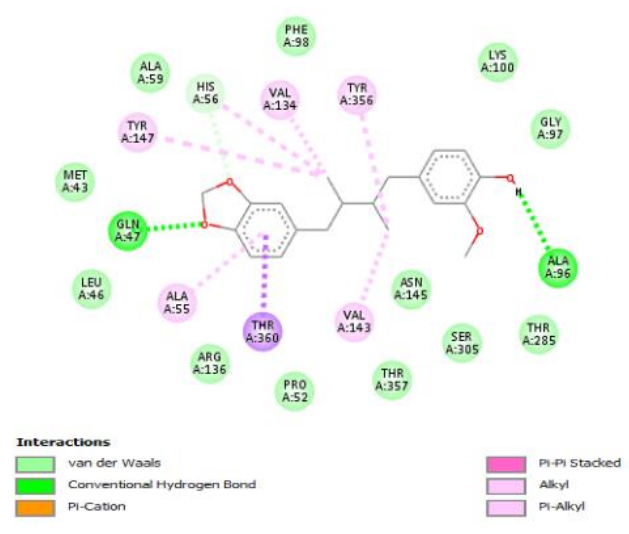

Figure 2. Two-dimensional interaction of macelignan and $\mathrm{DHODH}$

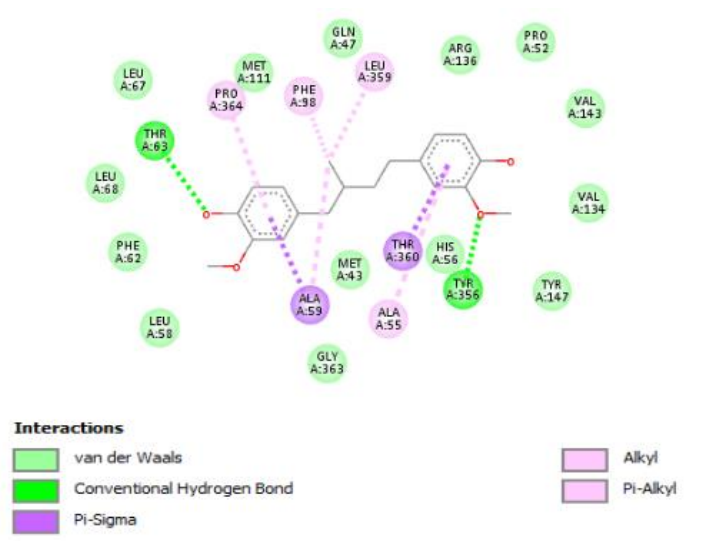

Figure 3. Two-dimensional interaction of dihydroguaiaretic acid

The molecular docking findings revealed a clear understanding and visual explanation of the nutmeg constituents and inhibitor binding mechanism. The same binding location and mode may be the same mechanism for inhibition [40]. However, the model established would be too early to be valid for compound anti-skin cancer without any experimental proof-the lower the energy, the stronger the 
binding between ligand-receptor complex. Docking simulations of the binding position of nutmeg constituents in the hydrophobic pocket of $\mathrm{DHODH}$ indicates the inhibition mechanism on the oxidoreductase activity of $\mathrm{DHODH}$. The combination mode and binding sites of $\mathrm{DHODH}$ and forty nutmeg compounds were studied by molecular simulation. Molecular docking is the most widely used approach for structure-based drug design and has many applications, such as binding energies and interaction [41]. The molecular docking method verified the good binding energy of 20 pairs of ligand-protein DHODH inhibitor complex.

\section{CONCLUSION}

The best interaction model of nutmeg constituents was dihydrogudiaretic acid with a binding energy score of $-9.3 \mathrm{kcal} / \mathrm{mol}$. The dihydroguaiaretic acid structure interacted with Tyr365 and Thr63 through a hydrogen bond similar to the native ligand. The result suggests that nutmeg seed could serve as the lead compound for potent $\mathrm{DHODH}$ inhibitor against skin cancer.

\section{ACKNOWLEDGEMENT}

This worked was supported by the Directorate General of Higher Education of Republic Indonesia Hibah PKPT DIKTI 2018 Grant Number: 228/SP2H/LT/DRPM/ 2019 , 001/LPPM-USB/Pekerti/V/2019.

\section{REFERENCES}

[1] K. Lee, S. Mun, H. Pyun, M. Kim, \& J. Hwang, "Effects of Macelignan Isolated from Myristica fragrans ( Nutmeg ) on Expression of Matrix Metalloproteinase-1 and Type I Procollagen in UVB-Irradiated
Human Skin Fibroblasts,"Biological and Pharmaceutical Bulletin vol. 35, no. October, pp. 1669-1675, 2012. DOI:10.1248/bpb.b12-00037

[2] Y. F. Dhaslin, R. Issac, \& M. L. Prabha, "Antioxidant, antimicrobial , and health benefits of nutmeg," Drug Invention Today, vol. 12, no. 1, pp. 2018-2020, 2019. DOI: 10.1016/B978-0-12-375688-6.10098-2

[3] C. Zhang, E. Jayashree, P. S. Kumar, \& M. G. Nair, "NPC Natural Product Communications," Natural Product Communicationspp. 8-11, 2015.

[4] S. R. Abbas \& S. Baig, "Treatment of Skin Cancer by Medicinal Plants [ A review ]," Journal of biotechnological sciences (vol. 137, no. 2, pp. 131-137, 2020.

[5] H. Chen, J. Nadas, A. Bode, \& K. Yao, "Prediction of Molecular Targets of Cancer Preventing Flavonoid Compounds Using Computational Methods," PloS one,vol. 7, no. 5, 2012.

DOI:10.1371/journal.pone.0038261

[6] J. Chavda \& H. Bhatt, "3D-QSAR ( CoMFA, CoMSIA, HQSAR and topomer CoMFA), MD simulations and molecular docking studies on purinylpyridine derivatives as BRaf inhibitors for the treatment of melanoma cancer," Structural Chemistry,2019. DOI: 10.1007/s11224-019-01334-9

[7] M. Hosseini, L. Dousset, P. Michon, \& W. Mahfouf "UVB-induced DHODH upregulation, which is driven by STAT3, is a promising target for chemoprevention and combination therapy of photocarcinogenesis," Oncogenesis, vol. 8, no. 10, 2019.

DOI: 10.1038/s41389-019-0161-z

[8] Y. Qian, X. Liang, P. Kong, Y. Cheng, H. Cui, T. Yan, "Elevated DHODH expression promotes cell proliferation via stabilizing $\beta$ catenin in esophageal squamous cell carcinoma," Cell Death Dis., vol. 11, no. 10, pp. 1-13, 2020. DOI: 10.1038/s41419-020-03044-1

[9] A. K. M. Fairus, B. Choudhary, S. Hosahalli, N. Kavitha, \& O. Shatrah, "Dihydroorotate dehydrogenase $(\mathrm{DHODH})$ inhibitors affect ATP depletion, endogenous ROS and mediate S-phase arrest in breast cancer 
cells," Biochimie, vol. 135, pp. 154-163, 2017.DOI: 10.1016/.biochi.2017.02.003Get

[10] U. D. Uysal, D. Ercengiz, O. Karaosmanoğlu, B. Berber, H. Sivas, \& H. Berber, "Theoretical and experimental electronic transition behaviour study of 2-((4(dimethylamino)benzylidene)amino)-4methylphenol and its cytotoxicity," J. Mol. Struct., vol. 1227, no. xxxx, 2021. DOI: $10.1016 /$ j.molstruc.2020.129370

[11] M.J.G.W. Ladds, \& I.M.M. Van Leeuwen "A DHODH inhibitor increases p53 synthesis and enhances tumor cell killing by p53 degradation blockage," Nat. Commun., vol. 9, no. 2018. DOI: 10.1038/s41467-018-03441-3

[12] S. Christian, C. Merz, L .Evans, S. Gradl, $\& H$. Seidel "The novel dihydroorotate dehydrogenase (DHODH) inhibitor BAY 2402234 triggers differentiation and is effective in the treatment of myeloid malignancies," Leukemia, vol. 33 , no. 10, pp. 2403-2415, 2019. DOI: 10.1038/s41375-019-0461-5

[13] L. Li, S.R. Ng, C.I. Colón, B.J. Drapkin, "Identification of DHODH as a therapeutic target in small cell lung cancer," Sci. Transl. Med., vol. 11, no. 517, 2019. DOI: $\quad$ 10.1126/scitransImed.aaw7852

[14] O. N. Reva, S. Rademan, M. H. Visagie, M. T. Lebelo, and V. Mokgadi, "Comparison of structures and cytotoxicity of mupirocin and batumin against melanoma and several other cancer cell lines,"Future medicinal chemistry, vol.1, no.7, pp. 677-691.2019. DOI: $10.4155 / \mathrm{fmc}-2018-0333$

[15] Z. Zabiulla, V. H. Malojirao, Y. Hussein, E. Mohammed, P. Thirusangu, \& S. A. Khanum, "CHEMISTRY Synthesis, molecular docking, and apoptogenic ef fi cacy of novel $\mathrm{N}$ heterocycle analogs to target B-cell lymphoma 2 / X-linked inhibitors of apoptosis proteins to regress melanoma," Med. Chem. Res., pp. 1132-1160, 2019. DOI: 10.1007/s00044-019-02357-x

[16] J. De Ruyck \& G. Brysbaert, "Molecular docking as a popular tool in drug design , an in silico travel," Advances and applications in bioinformatics and chemistry: $A A B C$, vol.9, no. 1, pp. 1-11, 2016. DOI: 10.2147/AABC.S105289x
[17] G. Kirishnamaline, J. D. Magdaline, T. Chithambarathanu, D. Aruldhas, \& A. R. Anuf, "Theoretical investigation of structure, anticancer activity and molecular docking of thiourea derivatives," J. Mol. Struct., vol. 1225, 2021.DOI:10.1016/.molstruc.2020.129118

[18] R. S. Ibrahim \& A. A. El-Banna, "Network pharmacology-based analysis for unraveling potential cancer-related molecular targets of Egyptian propolis phytoconstituents accompanied with molecular docking and in vitro studies ," RSC Adv., vol. 11, no. 19, pp. 11610-11626, 2021.

DOI: 10.1039/D1RA01390D

[19] S.A. Galal, A.S. Abdelsamie, H. Tokuda,\& N. Suzuki, "Part l: Synthesis, cancer chemopreventive activity and molecular docking study of novel quinoxaline derivatives," Eur. J. Med. Chem., vol. 46, no. 1 , pp. 327-340, 2011. DOI: 10.1016/j.ejmech.2010.11.022

[20] R. Baumgartner, M. Walloschek, M. Kralik, "Dual binding mode of a novel series of DHODH inhibitors," J. Med. Chem., vol. 49, no. 4, pp. 1239-1247, 2006.

DOI: 10.1021/jm0506975

[21] T. Narsinghani \& M. C. Sharma, "CHEMISTRY Synthesis, docking studies and antioxidant activity of some chalcone and aurone derivatives," Medicinal Chemistry Research, vol.22, no.9, pp. 4059-4068,2012. DOI: $10.1007 / s 00044-012-0413-3$

[22] Y.Y. Yang, Z.Y. Wu, H. Zhang, S.J. Yin, F.B. Xia, Q. Zhang, "LC-MS-based multivariate statistical analysis for the screening of potential thrombin/factor Xa inhibitors from Radix Salvia Miltiorrhiza," Chinese Med. (United Kingdom), vol. 15, no. 1, pp. 1-13, 2020. DOI: 10.1186/s13020-020-00320-2

[23] M. Alagumuthu \& S. Arumugam, "Molecular explorations of substituted 2 -( 4 - phenylquinolin - 2 - yl) phenols as phosphoinositide 3 - kinase inhibitors and anticancer agents," Cancer chemotherapy and pharmacology, vol.79, no.2, pp 389397.,2017.DOI: 10.1007/s00280-016-3227-z

[24] M. Arciniega \& J. L. Medina-franco, "Molecular docking: current advances and challenges," no. May, pp. 0-23, 2018. DOI: 10.22201/fesz.23958723e.2018.0.143 
[25] M. Gaba, A. Shaheed, B. Ajit, S. Jujhar, \& S. Memorial, "An overview on Molecular Docking International Journal of Drug Development \& Research, JSM Chem, vol.4, no.2, pp.10241028.2015. ISSN: 0975-9344"

[26] I. A. Guedes, C. S. De "Magalhães, \& L. E. Dardenne, "Receptor - ligand molecular docking," Biophysical reviews, vol.6, no.1, pp.75-87,2013.

DOI: 10.1007/s12551-013-0130-2"

[27] A. D. Gupta \& D. Rajpurohit, "Antioxidant and Antimicrobial Activity of Nutmeg (Myristica fragrans)," Nuts Seeds Heal. Dis. Prev., pp. 831-839,

2011.

DOI:10.1016/B978-0-12-375688-6.10098-2"

[28] V. Kuete, Myristica fragrans: A Review. Elsevier Inc., 2017.

DOI:10.1016/B978-0-12-809286-6.00023-6"

[29] A. Piras, A. Rosa, B. Marongiu, \& A. Atzeri., "Extraction and Separation of Volatile and Fixed Oils from Seeds of Myristica fragrans by Supercritical CO 2: Chemical Composition and Cytotoxic Activity on Caco-2 Cancer Cells," J. Food Sci., vol. 77, no. 4, pp. 1-6, 2012.

DOI: 10.1111/.1750-3841.2012.02618.x"

[30] S.M. Osman, N.A. Ayoub, S.A. Hafez,\& H.A. lbrahim, "Aldose reductase inhibitor form Cassia glauca: A comparative study of cytotoxic activity with Ag nanoparticles (NPs) and molecular docking evaluation," PLOS One, vol. 15, no. 10 October, 2020. DOI: 10.1371/journal.pone.0240856x"

[31] M. Sargolzaei, "Effect of nelfinavir stereoisomers on coronavirus main protease: Molecular docking, molecular dynamics simulation and MM/GBSA study," J. Mol. Graph. Model., vol. 103, p. 107803, 2021. DOI: 10.1016/j.jmgm.2020.107803"

[32] P. Ghosh, S. Bhakta, \& M. Bhattacharya "A Novel Multi-Epitopic Peptide Vaccine Candidate Against Helicobacter pylori: InSilico Identification, Design, Cloning and Validation Through Molecular Dynamics," Int. J. Pept. Res. Ther., no. 0123456789, 2021. DOI: 10.1007/s10989-020-10157-w"

[33] M. C. Vlasiou \& K. S. Pafti, "Screening possible drug molecules for Covid-19. The example of vanadium (III/IV/N) complex molecules with computational chemistry and molecular docking," Comput. Toxicol., vol. 18, no. August 2020, 2021.

DOI: 10.1016/j.comtox.2021.100157

[34] X. Lin, X. Li, \& X. Lin, "A review on applications of computational methods in drug screening and design," Molecules, vol. 25, no. 6, pp. 117, 2020.DOI: 10.3390/molecules25061375

[35] X.-Y. Meng, H.-X. Zhang, M. Mezei, \& M. Cui, "Molecular Docking: A Powerful Approach for Structure-Based Drug Discovery," Curr. Comput. Aided-Drug Des., vol. 7, no. 2, pp. 146-157, 2012. DOI: 10.2174/1573409117956776025"

[36] F. Rahman, S. Tabrez, R. Ali, A. S. Alqahtani, M. Z. Ahmed, \& A. Rub, "Molecular docking analysis of rutin reveals possible inhibition of SARS-CoV-2 vital proteins," J. Tradit. Complement. Med., vol. 11, no. 2, pp. 173179, 2021.DOI: 10.1016/j.jtcme.2021.01.006"

[37] L. Metterle, C. Nelson, \& N. Patel, "Intralesional 5-fluorouracil (FU) as a treatment for nonmelanoma skin cancer (NMSC): A review," J. Am. Acad. Dermatol., vol. 74, no. 3, pp. $\quad 5016$. DOI: 10.1016/j.jaad.2015.09.040"

[38] D.M Rata, A.N Cadinoiu, L.I Atanase\&, M. Popa, "Topical formulations containing aptamer-functionalized nanocapsules loaded with 5-fluorouracil - An innovative concept for the skin cancer therapy," Mater. Sci. Eng. C, vol. 119, no. 11, p. 111591, 2021. DOI: 10.1016/j.msec.2020.111591"

[39] E. A. A. A. T. El-alfy, "Chemical diversity and pharmacological significance of the secondary metabolites of nutmeg ( Myristica fragrans Houtt.)," Phytochem. Rev., 2016. DOI: $\quad$ 10.1007/s11101-016-9469-x"

[40] A.R Zuo, H.H Dong, Y.Y Yu, Q.L Shu, L.X Zheng,\& X.Y Yu, "The antityrosinase and antioxidant activities of flavonoids dominated by the number and location of phenolic hydroxyl groups," Chinese Med. (United Kingdom), vol. 13, no. 1, pp. 1-12, 2018. DOI: 10.1186/s13020-018-0206-9"

[41] Y. Zhang, X. Mao, J. Su, Y. Geng, R. Guo, "A network pharmacology-based strategy deciphers the underlying molecular mechanisms of Qixuehe Capsule in the treatment of menstrual disorders," Chinese Med. (United Kingdom), vol. 12, no. 1, pp. 111, 2017.DOI: 10.1186/s13020-017-0145-x" 